\title{
Effect Of An Extra-Virgin Olive Oil Intake On The Delay Of Cognitive Decline: Role Of Secoiridoid Oleuropein?
}

This article was published in the following Dove Press journal:

Neuropsychiatric Disease and Treatment

\section{Blanka Klimova $\mathbb{D D}^{1}$ \\ Michal Novotný ${ }^{2}$ \\ Kamil Kuca $\mathbb{( D D}^{2-4}$ \\ Martin Valis ${ }^{5}$}

'Department of Applied Linguistics, University of Hradec Kralove, Hradec Kralove 500 03, Czech Republic;

${ }^{2}$ Biomedical Research Centre, University Hospital Hradec Kralove, Hradec

Kralove, Czech Republic; ${ }^{3}$ Department of Chemistry, Faculty of Science, University of Hradec Kralove, Hradec Kralove, Czech Republic; ${ }^{4}$ Malaysia Japan International Institute of Technology (MJIIT), Universiti Teknologi Malaysia Kuala Lumpur, Jalan Sultan Yahya Petra, Kuala Lumpur 54100, Malaysi;

${ }^{5}$ Department of Neurology, University Hospital Hradec Kralove, Hradec Kralove 500 05, Czech Republic
Correspondence: Kamil Kuca

University Hospital, Sokolska 58I, Hradec Kralove, Czech Republic

Tel +420603289166

Fax +420 495835200

Email kamil.kuca@fnhk.cz

\begin{abstract}
Currently, there is an increase in the number of the world's aging population. This aging process is often connected with cognitive decline of some functions such as memory or speed processing loss. Since Alzheimer's disease cannot be cured yet, considerable efforts are being made to at least delay this cognitive decline among elderly in order to maintain and prolong the quality of their life. This can also be achieved by non-pharmacological approaches such as performing physical activities, cognitive training, or adhering to a Mediterranean Diet (MedDiet). One of the components of MedDiet - extra-virgin olive oil (EVOO) - has considerable health benefits. The purpose of this review is to examine the effect of EVOO intake on the delay of cognitive decline among the elderly. The methodology is based on a literature review of available sources found on the research topic in three acknowledged databases: Web of Science, Scopus, and PubMed. The results of in vitro and in vivo studies indicate that the regular intake of EVOO is associated with enhanced cognitive functions, which means that this oil may have a neuroprotective effect and could positively prevent the development of dementia, especially Alzheimer's dementia. It is believed that secoiridoid oleuropein is responsible for this effectiveness. Furthermore, there is also a need of more randomized controlled studies or longitudinal observational studies to be performed to confirm the efficacy of the beneficial health effect of EVOO on the delay of cognitive decline.
\end{abstract}

Keywords: extra-virgin olive oil, oleuropein, oleuropein-aglycone, cognitive decline, Alzheimer disease, review

\section{Introduction}

As demographic trends indicate, there is an increase in the number of the world's aging population. In 2017, there was almost one billion adults at the age of $60+$ years. In 2050, this number should be 2-times higher. Europe has the largest share $(25 \%)$ of this population group. ${ }^{1}$ This aging process is often connected with cognitive decline of some functions, such as memory or speed processing loss. ${ }^{2}$ In some cases, cognitive decline can result in mild cognitive impairment (MCI) affecting everyday living. MCI is a forerunner of Alzheimer's disease (AD). In fact, $\mathrm{AD}$ is the most common cause of cognitive decline among the elderly. Research shows that, at the age of 65 , nearly $5 \%$ of older people suffer from AD and, by the age of 85 , it is more than $40 \% .^{3}$ Thus, apart from cognitive decline, the main symptoms of $\mathrm{AD}$ include difficulties in orientation, language disorders, changes in mood, loss of motivation, inability to manage self-care, or behavioral disorders. ${ }^{4,5}$ 
Since AD cannot be cured yet, considerable efforts are being made to at least delay this cognitive decline among elderly in order to maintain and prolong the quality of their life. This is done, for example, by non-pharmacological approaches such as performing physical activities, cognitive training, or adhering to a Mediterranean Diet (MedDiet). ${ }^{2,6-10}$

In addition, research ${ }^{11-18}$ reveals that one of the components of MedDiet (extra-virgin olive oil) has considerable health benefits. Apart from the protection against cardiovascular diseases, cancer, type 2 diabetes mellitus, or obesity, it plays an important role in the delay of the age-related cognitive decline. Recently, it has been published that poor adherence to the MedDiet may have a negative influence on academic performance in adolescents ${ }^{19}$ and contrary MedDiet well adherent female adolescents were associated with a reduced presence of depressive symptoms. ${ }^{20}$ Olive oil is a fatty acids and antioxidants-rich food, whose best quality form is extra-virgin olive oil (EVOO). Consumption of EVOO is connected with lower mitochondrial oxidative stress, which might counteract age-related cognitive decline. ${ }^{21-23}$ It seems that secoiridoid oleuropein, resp. oleuropein aglycone, is responsible for its neuroprotective effect. ${ }^{24}$

The purpose of this review is to examine the effect of EVOO intake on the delay of cognitive decline among elderly.

\section{Methods}

The methods are based on a literature review of available sources found on the research topic in three acknowledged databases: Web of Science, Scopus, and PubMed. The search was not limited by any time period. The oldest study dates back to $1973^{25}$ and the latest to November $2018 .^{26}$ The literature search was conducted between November 20, 2018, and December 20, 2018, to identify published peer-reviewed articles in English. The collocated keywords were as follows: olive oil AND cognitive decline, olive oil AND cognitive impairment, extra-virgin olive oil AND cognitive decline, extra-virgin olive oil AND cognitive decline, extra-virgin olive oil AND cognitive impairment, extra-virgin olive oil AND cognitive impairment. The keywords were combined and integrated in database and journal searches. The terms used were searched using AND to combine the keywords listed and using OR to remove search duplication where possible. References of retrieved articles were assessed for relevant articles that authors' searches may have missed. Both in vitro and in vivo studies were included.

\section{Findings}

\section{Chemistry And Pharmacology Of Olive Oil - Oleuropein}

The benefits of olives or olive oil have been observed on the basis of dietary effects on human health. The positive pharmacological properties of olive oil are mainly due to the phenolic content. ${ }^{27}$ The most significant representatives of the phenolic oleosides in Olea europaea are: oleuropein, dimethyl-oleuropein, ligstroside, and oleoside. Oleuropein has the largest proportion of them and its content in young olives can be as high as $140 \mathrm{mg} / \mathrm{g}$ of dry matter. ${ }^{28,29}$ Oleuropein (Figure 1) belongs to a group of polyphenols called secoiridoids. The molecule of oleuropein has three subunits: a polyphenol, namely 4-(2-hydroxyethyl) benzene-1,2-diol (also known as hydroxytyrosol), a secoiridoid called elenolic acid, and a molecule of glucose. ${ }^{30}$ Oleuropein-aglycone (Figure 2) originates from it in the production of EVOO, where mechanical crushing and pressing takes place, as well as the physiological release of the $\beta$-glucosidase enzyme, which can cleave ester bonds. ${ }^{24,31}$ EVOO is the best form of olive oil and, thanks to its production technology (mechanical pressing of ripe olives), it retains most of its lipophilic components compared to ordinary olive oil (virgin and refined oil). It is believed that it is just oleuropein-aglycone, which has a neuroprotective effect. $^{32-34}$

Several in vitro and in vivo studies have shown the pleiotropic effect of oleuropein and its derivatives. The positive properties of oleuropein included antioxidant,

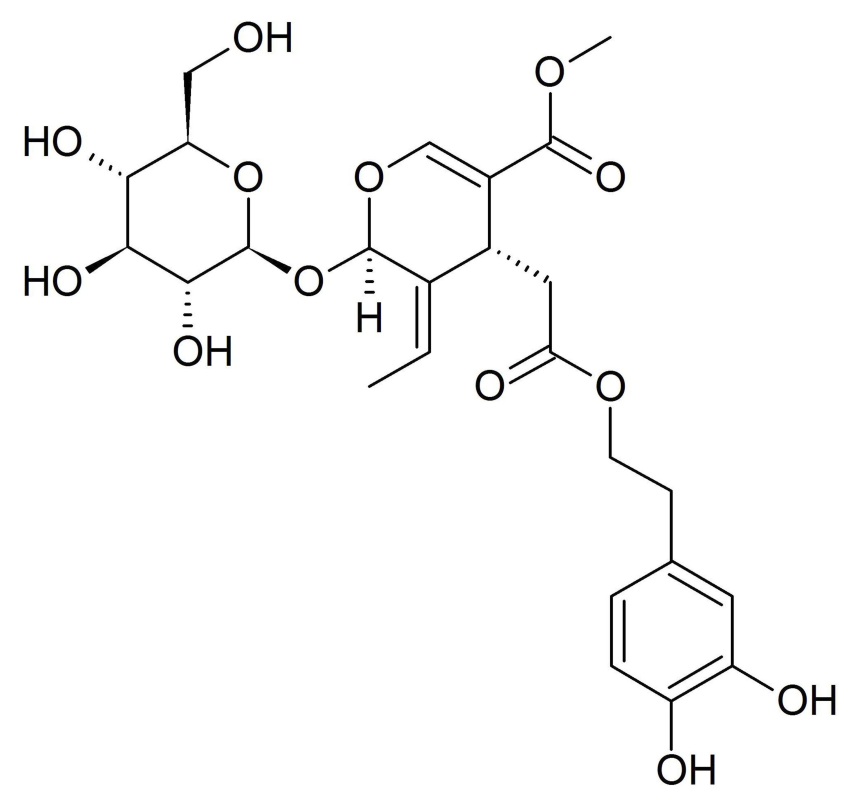

Figure I Chemical formula of oleuropein. 


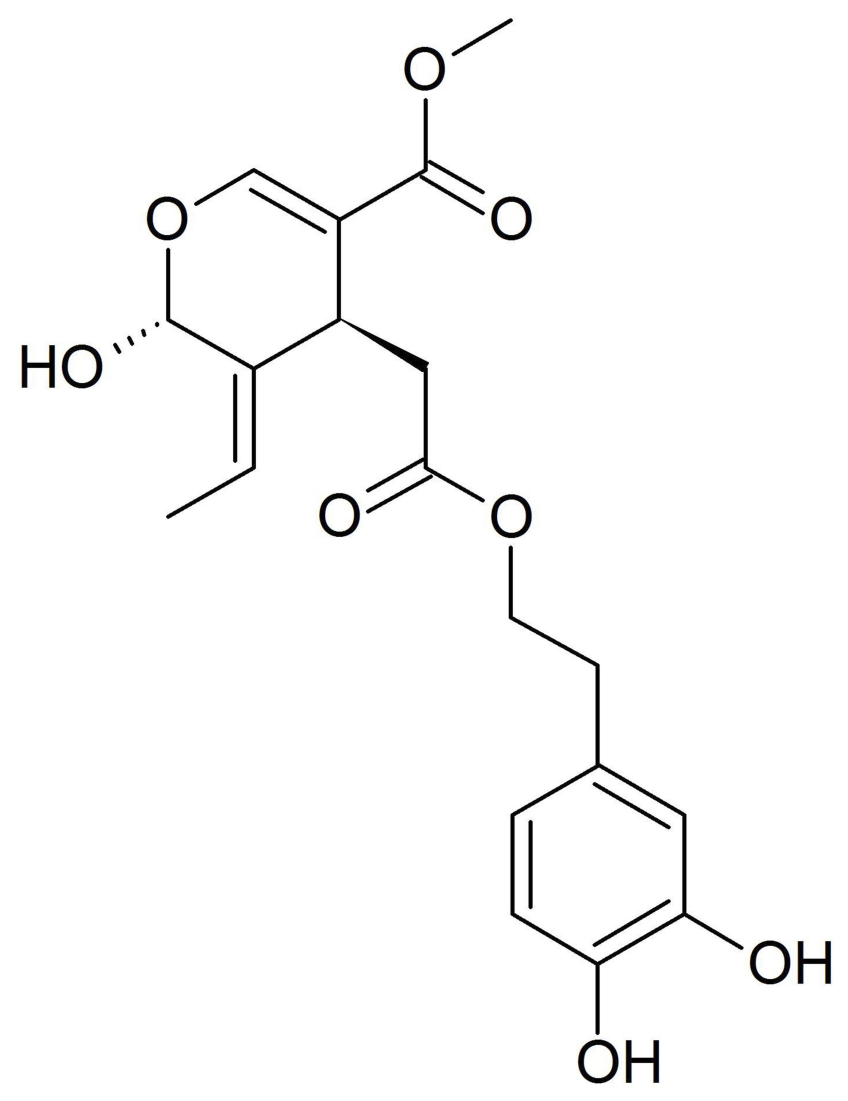

Figure 2 Chemical formula of oleuropein-aglycone.

antidiabetic, antimicrobial, antiviral, antitumor, hepatoprotective, cardioprotective, anti-aging, anti-inflammatory, and also neuroprotective effects. ${ }^{35}$ An overview of the most significant effects of oleuropein is provided in Table 1.

Clinical studies on olive oil, EVOO, or oleuropein studies, currently running, are described in Table 2 (Phase: recruiting or not yet recruiting, https://clinicaltrials.gov). It can be seen from the following that phenolic oleosides are a popular group of pharmacologically active substances among scientists, potentially suitable for affecting many different diseases (eg, hypertension, Alzheimer's disease, Ulcerative disease, DM2,...).

\section{Animal Studies Of Oleuropein In Neuroprotection}

The available data indicate that the administration of EVOO in particular oleuropein-aglycone intake has a neuroprotective effect in animal models. As is summarized in Table 3, memory functions and behavior are significantly improved. In terms of the protective action of oleuropein-aglycone, mechanisms are offered including: inhibition of $A \beta$ aggregation, reduction of $\mathrm{A} \beta$ aggregate toxicity, promotion of natural autophagy, and lysosomal function. Equally important seems to be its anti-inflammatory properties.

\section{Human Studies With EVOO As Neuroprotection}

The authors detected only two studies ${ }^{13,36}$ in which EVOO was tested against cognitive decline. They were both randomized controlled trials. The Italian study ${ }^{13}$ examined whether the replacement of all vegetable oils with a lower amount of extra-virgin olive oil, in the contest of a MedDiet, would affect cognitive functions among the Italian elderly. It lasted for 1 year. In total, 110 healthy elderly subjects at the mean age of 70 participated. Fiftyfive subjects were taking a Mediterranean diet (MedDiet) and 55 subjects in the experimental group were taking MedDiet plus EVOO. Extra-virgin Olive Oil intake was $30 \pm 12 \mathrm{~g}$ and $26 \pm 6 \mathrm{~g}$ in the MedDiet and MedDiet plus EVOO groups, respectively ( $p=0.044)$. The results revealed that the higher short-term improvement of cognitive functions scores was in subjects on a MedDiet plus low dose of extra-virgin olive oil rather than MedDiet alone. EVOO, thus, may have a neuroprotective effect.

The second, Spanish study, ${ }^{36}$ evaluated the effect on cognition of a controlled intervention testing MedDiet. It lasted for 6.5 years. There were 285 non-demented subjects, out of which $44.8 \%$ were males and $55.2 \%$ were females. The mean age at cognitive evaluation was 74.1 \pm 5.7 years. The results showed that a long-term intervention with an EVOO-rich MedDiet resulted in a better cognitive function in comparison with a control diet. Subjects with an EVOO-rich MedDiet had less MCI than controls. Thus, the neuroprotective effect against cognitive decline was confirmed.

\section{Discussion}

EVOO is the best quality oil produced by mechanical pressing of ripe olives. Through this process, it is possible to retain most of the components with strong antioxidant and antiinflammatory properties. Any industrial processing of olive oil (extraction and refining) makes it a lower quality oil. Comparing EVOO with refined olive oil, the refined form is less protective of oxidative lipid damage, free radical formation, and inflammatory activity. Oleuropein-aglycone, which is the chief phenolic substance of extra virgin olive oil, and the neuroprotective effect is thought to be associated with $^{13}{ }^{13}$

The results of both in vitro and vivo studies show that oleuropein-aglycone, which is an important phenolic component of EVOO has a positive neuroprotective effect against cognitive decline. ${ }^{13,36-42}$ This especially concerns memory functions and behavior. 
Table I The Most Important Effects Of Oleuropein

\begin{tabular}{|c|c|c|}
\hline Property & Observed Effects & References \\
\hline Antioxidant & $\begin{array}{l}\text { Inhibits of oxidation of low-density lipoproteins (LDL) } \\
\text { Scavenges nitric oxide; increase inducible nitric oxide synthase expression } \\
\text { Induction of the inducible nitric oxide synthase in macrophages } \\
\text { Increases the ability of LDL to resist oxidation; reduces the plasma levels of total, free, and esterified } \\
\text { cholesterol } \\
\text { Antioxidant effects in leukocytes } \\
\text { Lower lipid peroxidation }\end{array}$ & $\begin{array}{l}54,55 \\
56 \\
57 \\
58 \\
59 \\
57\end{array}$ \\
\hline Anti-inflamatory & Inhibitis lipoxygenase activity and the production of leukotriene B4 & 59 \\
\hline Anti-atherogenic & $\begin{array}{l}\text { Reduces monocytoid cell adhesion to endothelium and reduces } \\
\text { cell adhesion molecule-I mRNA and protein }\end{array}$ & 60 \\
\hline Anti-cancer & $\begin{array}{l}\text { Inhibits growth cancer cells (LN-I8, TF-Ia, 786-O, T-47D, RPMI-795I, LoVo) } \\
\text { Decreases breast cancer cell viability } \\
\text { Reduces the viability of MCF-7 by inducing cell apoptosis } \\
\text { Inhibits cell proliferation (MCF-7, T-24, BBCE) }\end{array}$ & $\begin{array}{l}61 \\
62 \\
63 \\
64\end{array}$ \\
\hline Anti-microbial & $\begin{array}{l}\text { Strong antimicrobial activity against gram-negative and gram-positive bacteria } \\
\text { Antimicrobial activity against mycoplasma } \\
\text { Able to inhibit the development of: Staphylococcus aureus, Salmonella enteritidis, Bacillus cereus, } \\
\text { Klebsiella pneumoniae, Escherichia coli, Campylobacter jejuni, Helicobacter pylori }\end{array}$ & $\begin{array}{l}65,66 \\
67 \\
68-72\end{array}$ \\
\hline Antiviral & $\begin{array}{l}\text { Antiviral against: herpes mononucleosis, hepatis virus, rotavirus, bovine rhinovirus, canine parvovirus, } \\
\text { feline leukemia virus } \\
\text { Antiviral against: respiratory syncytial virus and para-influenza type } 3 \text { virus }\end{array}$ & 73 \\
\hline
\end{tabular}

Animal model studies have suggested a possible mechanism of action associated with this improvement in cognitive function. It is an induction of autophagy, which in turn reduces the amount of $A \beta$ aggregates. Another ability is to utilize the cytotoxicity of accumulated $A \beta$ and reduce inflammation from activated astrocytes and microglia. One of the mechanisms by which the extra-virgin oil exerts this effect includes the increase in the antioxidant content of low density lipoproteins and the nutrigenomic effect. ${ }^{43} \mathrm{~A}$ great advantage is that EVOO does not show any adverse effects such as cell death or apoptosis (curcumin) or neurodegeneration (rapamycin). ${ }^{13,17,23,35,44}$

Due to the complexity and possible distance of these studies, there are no direct studies of the mechanism of action and physiological effect of EVOO on the human body. All available human data are based on extrapolation from animal models. However, it is seriously assumed that EVOO is a useful food to prevent and alleviate the symptoms associated with AD. However, more studies are needed to test human effects, particularly in terms of metabolic pathways and bioavailability. The fact is that the effects of EVOO on gene expression have not yet been studied. $^{35}$
As general recommendations state, the protective effect of virgin olive oil can be most important in the first decades of life, which suggests that the health benefit of virgin olive oil intake should start before puberty, and maintained through life. ${ }^{11,16}$

The limitations of this review are related to a relatively small number of the studies with humans, their different methodologies, and studying the effect of EVOO together with the MedDiet. All this can lead to the overestimation of the discussed results.

\section{Conclusion}

Much evidence shows the beneficial effects of Mediterranean diet as an effective prevention of neurodegenerative diseases. As Mediterranean diet is characterized by high consumption of extra virgin olive oil, it is believed that the complex of biomolecules, led by oleuropein-aglycon, contained in EVOO, may be responsible for the beneficial effect of Mediterranean diet. The beneficial effects of olive oil and its biomolecules on neurological disorders have been extensively investigated from the perspective of different cell pathways. Studies demonstrating the protective activity of oleuropein-aglycone include: against LDL oxidation, ${ }^{45}$ 


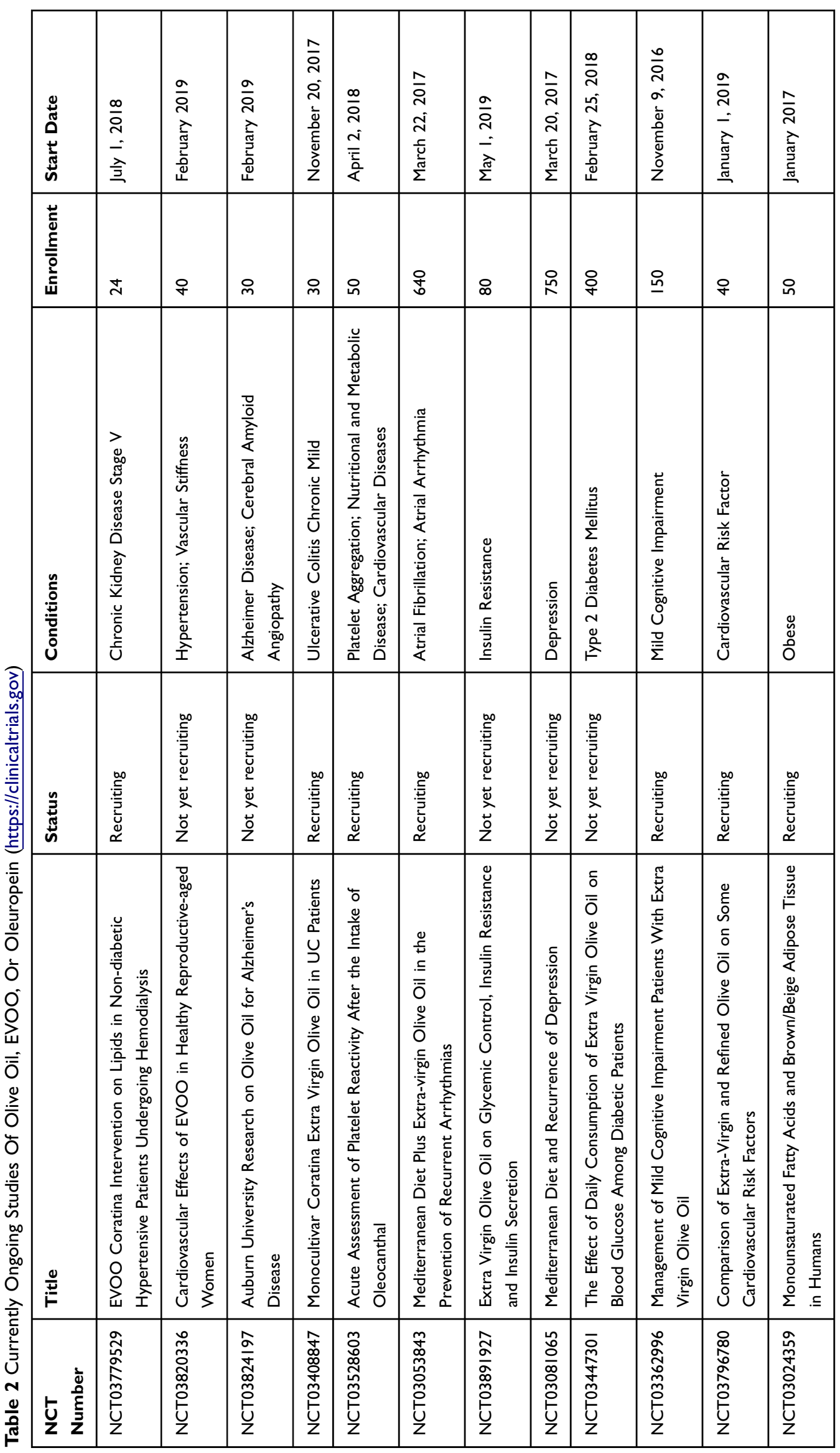


Table 3 Animal Studies Of Oleuropein In Neuroprotection

\begin{tabular}{|c|c|c|}
\hline Animal & Result & References \\
\hline C57BI/6J mice & $\begin{array}{l}\text { Enhanced contextual memory; reduced age-related impairment in motor coordination; lipid } \\
\text { peroxidation and inflammation markers were decreased in brain areas connected with motor control }\end{array}$ & 37 \\
\hline TgCRND8 mice & $\begin{array}{l}\text { Ameliorated memory dysfunction; reduced } \beta \text {-amyloid levels and plaque deposits; increase of } \\
\text { autophagic markers expression through mTOR inhibition }\end{array}$ & 38 \\
\hline TgCRND8 mice & $\begin{array}{l}\text { Massive reduction of pyroglutamate- } 3 \text { amyloid- } \beta \text { protein (major component of } \beta \text {-amyloid } \\
\text { plaque) by reducing its aggregation }\end{array}$ & 39 \\
\hline Wistar rat & $\begin{array}{l}\text { Reduced the toxicity of } A \beta \text { aggregated; reduced the amount of soluble } A \beta \text { oligomers; no } \\
\text { evident inflammatory reaction }\end{array}$ & 40 \\
\hline CL2600 Caenorhabditis elegans & Reduction in the plaque deposition; less abundant toxic $A \beta$ oligomers & 41 \\
\hline
\end{tabular}

against oxidative stress at the brain level, ${ }^{46,47}$ to reduce the volume of cerebral infarction after cerebral ischemia/reperfusion injury in mice, ${ }^{48}$ reduction of inflammatory biomarkers (TNF- $\alpha$, IL-l $\alpha$, iNOS, COX-2) after spinal cord injury (animal model), ${ }^{49,50}$ interference with amyloid aggregation (in vitro), ${ }^{51}$ reduction in A $\beta 42$ deposits (animal models), ${ }^{41}$ suppression of $\mathrm{pE} 3-\mathrm{A} \beta$ production, ${ }^{52}$ and reduction of oxidative stress and apoptosis induced by 6-OHDA (in vitro). ${ }^{53}$

Moreover results of this study show that the use of secoiridoid oleuropein-aglycone which is present in EVOO in diet has a positive impact on the delay of cognitive decline among non-demented older individuals. In addition, there is a longitudinal association between this oil consumption and cognitive decline.

Furthermore, there is a need of more randomized controlled studies or longitudinal observational studies to be performed to confirm the efficacy of the beneficial health effect of oleuropein-aglycone respective EVOO on the delay of cognitive decline.

\section{Acknowledgment}

This paper was supported by SPEV project (2104/2019) run at the Faculty of Informatics and Management of the University of Hradec Kralove; by the project IT4Neuro(degeneration), reg. nr. CZ.02.1.01/0.0/0.0/18_069/0010054. Also supported by the project (Ministry of Health, Czech Republic) for conceptual development of research organization 00179906.

\section{Disclosure}

The authors have no conflicts of interest to report in this work.

\section{References}

1. United Nations. Ageing. Available from: http://www.un.org/en/sec tions/issues-depth/ageing/. Accessed January 8, 2019.
2. Klimova B, Valis M, Kuca K. Cognitive decline in normal aging and its prevention: A review on non-pharmacological lifestyle strategies. Clin Interv Aging. 2017;12:903-910. doi:10.2147/CIA.S132963

3. Alzheimer's Association. 2014 Alzheimer's disease facts and figures. Alzheimers Dement. 2014;10(2):e47-e92.

4. Klimova B, Maresova P, Kuca K. Non-pharmacological approaches to the prevention and treatment of Alzheimer's disease with respect to the rising treatment costs. Curr Alzheimer Res. 2016;13(11):1249-1258.

5. Klimova B, Maresova P, Valis M, Hort J, Kuca K. Alzheimer's disease and language impairments: social intervention and medical treatment. Clin Interv Aging. 2015;10:1401-1408. doi:10.2147/CIA.S89714

6. Hardman RJ, Kennedy G, Macpherson H, Scholey AB, Pipingas A. A randomised controlled trial investigating the effects of mediterranean diet and aerobic exercise on cognition in cognitively healthy older people living independently within aged care facilities: the Lifestyle Intervention in Independent Living Aged Care (LIILAC) study protocol [ACTRN12614001133628]. Nutr J. 2015;14:53.

7. Hardman RJ, Kennedy G, Macpherson H, Scholey AB, Pipingas A. Adherence to a Mediterranean-style diet and effects on cognition in adults: a qualitative evaluation and systematic review of longitudinal and prospective trials. Front Nutr. 2016;3:22. doi:10.3389/fnut.2016.00022

8. Klimova B. Computer-based cognitive training in aging. Front Aging Neurosci. 2016;8:313. doi:10.3389/fnagi.2016.00313

9. Kivipelto M, Solomon A, Ahtiluoto S, et al. The Finnish Geriatric Intervention Study to Prevent Cognitive Impairment and Disability (FINGER): study design and progress. Alzheimers Dement. 2013;9 (6):657-665. doi:10.1016/j.jalz.2012.09.012

10. Ngandu T, Lehtisalo J, Solomon A, et al. A 2 year multidomain intervention of diet, exercise, cognitive training, and vascular risk monitoring versus control to prevent cognitive decline in at-risk elderly people (FINGER): a randomised controlled trial. Lancet. 2015;385(9984):2255-2263. doi:10.1016/S0140-6736(15) 60461-5

11. Visioli F, Franco M, Toledo E, et al. Olive oil and prevention of chronic diseases: summary of an international conference. Nutr Metab Cardiovasc Dis. 2018;28(7):649-656. doi:10.1016/j.numecd.2018.04.004

12. Locke A, Schneiderhan J, Zick SM. Diets for health: goals and guidelines. Am Fam Physician. 2018;97(11):721-728.

13. Mazza E, Fava A, Ferro Y, et al. Effect of the replacement of dietary vegetable oils with a low dose of extravirgin olive oil in the mediterranean diet on cognitive functions in the elderly. $J$ Transl Med. 2018;16(1):10. doi:10.1186/s12967-018-1386-x

14. López-Miranda J, Pérez-Jiménez F, Ros E, et al. Olive oil and health: summary of the II international conference on olive oil and health consensus report, Jaén and Córdoba (Spain) 2008. Nutr Metab Cardiovasc Dis. 2010;20(4):284-294. doi:10.1016/j. numecd.2009.12.007 
15. Delgado-Lista J, Garcia-Rios A, Perez-Martinez P, Lopez-Miranda J, Perez-Jimenez F. Olive oil and haemostasis: platelet function, thrombogenesis and fibrinolysis. Curr Pharm Des. 2011;17(8):778-785. doi:10.2174/138161211795428876

16. Perez-Jimenez F, Alvarez de Cienfuegos G, Badimon L, et al. International conference on the healthy effect of virgin olive oil. Eur J Clin Invest. 2005;35(7):421-424. doi:10.1111/j.13652362.2005.01516.x

17. Covas MI, de la Torre R, Fito M. Scientific evidence of the benefits of virgin olive oil for human health. Med Balear. 2014;29(2):39-46.

18. Martinez-Gonzalez MA, Martin-Calvo N. Mediterranean diet and life expectancy; beyond olive oil, fruits, and vegetables. Curr Opin Clin Nutr Metab Care. 2016;19(6):401-407. doi:10.1097/ MCO.0000000000000316

19. Vassiloudis I, Yiannakouris N, Panagiotakos DB, Apostolopoulos K, Costarelli V. Adherence to the mediterranean diet and specific lifestyle habits are associated with academic performance in Greek adolescents. MNM. 2017;10(2):93-103. doi:10.3233/MNM-16133

20. Tehrani AN, Salehpour A, Beyzai B, et al. Adherence to Mediterranean dietary pattern and depression, anxiety and stress among high-school female adolescents. MNM. 2018;11(1):73-83. doi:10.3233/MNM-17192

21. Valls-Pedret C, Lamuela-Raventós RM, Medina-Remón A, et al. Polyphenol-rich foods in the mediterranean diet are associated with better cognitive function in elderly subjects at high cardiovascular risk. J Alzheimers Dis. 2012;29(4):773-782. doi:10.3233/JAD-2012111799

22. Quiles JL, Barja G, Battino M, Mataix J, Solfrizzi V. Role of olive oil and monounsaturated fatty acids in mitochondrial oxidative stress and aging. Nutr Rev. 2006;64(s4):31-39. doi:10.1111/j.1753-4887.2006. tb00170.x

23. St-Laurent-Thibault C, Arseneault M, Longpré F, Ramassamy C. Tyrosol and hydroxytyrosol, two main components of olive oil, protect $\mathrm{N} 2 \mathrm{a}$ cells against amyloid- $\beta$-induced toxicity. Involvement of the NF- $\mathrm{KB}$ signaling. Curr Alzheimer Res. 2011;8(5):543-551.

24. Martorell M, Forman K, Castro N, Capó X, Tejada S, Sureda A. Potential therapeutic effects of oleuropein aglycone in Alzheimer's disease. Curr Pharm Biotechnol. 2016;17:994-1001. doi:10.2174/ 1389201017666160725120656

25. Fleming HP, Walter WM, Etchells JL. Antimicrobial properties of oleuropein and products of its hydrolysis from green olives. Appl Microbiol. 1973;26:777-782.

26. Morley JE. An overview of cognitive impairment. Clin Geriatr Med. 2018;34(4):505-513. doi:10.1016/j.cger.2018.06.003

27. Visioli F, Poli A, Gall C. Antioxidant and other biological activities of phenols from olives and olive oil. Med Res Rev. 2002;22:65-75.

28. Soler-Rivas C, Espín JC, Wichers HJ. Oleuropein and related compounds. J Sci Food Agric. 2000;80:1013-1023. doi:10.1002/(SICI) 1097-0010(20000515)80:7<1013::AID-JSFA571>3.0.CO;2-C

29. Amiot MJ, Fleuriet A, Macheix JJ. Accumulation of oleuropein derivatives during olive maturation. Phytochemistry. 1989;28:67-69. doi:10.1016/0031-9422(89)85009-5

30. Omar SH. Cardioprotective and neuroprotective roles of oleuropein in olive. Saudi Pharm J. 2010;18(3):111-121. doi:10.1016/j. jsps.2010.05.005

31. Rigacci S. Olive oil phenols as promising multi-targeting agents against Alzheimer's disease. Adv Exp Med Biol. 2005;863:1-20.

32. Barbaro B, Toietta G, Maggio R, et al. Effects of the olive-derived polyphenol oleuropein on human health. IJMS. 2014;15(10):1850818524.

33. Xu F, Li Y, Zheng M, Xi X, Zhang X, Han C. Structure properties, acquisition protocols, and biological activities of oleuropein aglycone. Front Chem. 2018;6:239. doi:10.3389/fchem.2018.00239

34. Angeloni C, Malaguti M, Barbalace M, Hrelia S. Bioactivity of olive oil phenols in neuroprotection. IJMS. 2017;18(11):2230. doi:10.3390/ ijms 18112230
35. Cordero JG, García-Escudero R, Avila J, Gargini R, García-Escudero V. Benefit of oleuropein aglycone for Alzheimer's disease by promoting autophagy. Oxid Med Cell Longev. 2018;2018:5010741. doi:10.1155/2018/5010741

36. Martínez-Lapiscina EH, Clavero P, Toledo E, et al. Virgin olive oil supplementation and long-term cognition: the PREDIMEDNAVARRA randomized, trial. $J$ Nutr Health Aging. 2013;17 (6):544-552. doi:10.1007/s12603-013-0027-6

37. Pitozzi V, Jacomelli M, Catelan D, et al. Long-term dietary extra-virgin olive oil rich in polyphenols reverses age-related dysfunctions in motor coordination and contextual memory in mice: role of oxidative stress. Rejuvenation Res. 2012;15:601-612. doi:10.1089/rej.2012.1346

38. Grossi C, Rigacci S, Ambrosini S, et al. The polyphenol oleuropein aglycone protects TgCRND8 mice against $\mathrm{A} \beta$ plaque pathology. PLoS One. 2013;8:e71702. doi:10.1371/journal.pone.0071702

39. Grossi C, Dami TE, Rigacci S, Stefani M, Luccarini I, Casamenti F. Employing Alzheimer disease animal models for translational research: focus on dietary components. Neurodegener Dis. 2014;13:131-134. doi:10.1159/000355461

40. Luccarini I, Dami TE, Grossi C, Rigacci S, Stefani M, Casamenti F. Oleuropein aglycone counteracts $\mathrm{A} \beta 42$ toxicity in the rat brain. Neurosci Lett. 2014;558:67-72. doi:10.1016/j.neulet.2013.10.062

41. Diomede L, Rigacci S, Romeo M, Stefani M, Salmona M. Oleuropein aglycone protects transgenic $\mathrm{C}$. elegans strains expressing A $\beta 42$ by reducing plaque load and motor deficit. PLoS One. 2013;8: e58893. doi:10.1371/journal.pone.0058893

42. Lauretti E, Iuliano L, Praticò D. Extra-virgin olive oil ameliorates cognition and neuropathology of the 3xTg mice: role of autophagy. Ann Clin Transl Neurol. 2017;4(8):564-574. doi:10.1002/acn3.431

43. Gorzynik-Debicka M, Przychodzen P, Cappello F, et al. Potential health benefits of olive oil and plant polyphenols. Int $\mathrm{J} \mathrm{Mol} \mathrm{Sci}$. 2018;19(3):pii,E6. doi:10.3390/ijms19030686

44. Rigacci S. Olive oil phenols as promising multi-targeting agents against Alzheimer's disease. Adv Exp Med Biol. 2015;863:1-20. doi:10.1007/978-3-319-18365-7 1

45. Visioli F, Galli C. Oleuropein protects low density lipoprotein from oxidation. Life Sci. 1994;55(24):1965-1971. doi:10.1016/0024-3205 (94)00529-x

46. Ogun M, Ozcan A, Karaman M, et al. Oleuropein ameliorates arsenic induced oxidative stress in mice. J Trace Elem Med Biol. 2016;36:16. doi:10.1016/j.jtemb.2016.03.006

47. Peng S, Zhang B, Yao J, Duan D, Fang J. Dual protection of hydroxytyrosol, an olive oil polyphenol, against oxidative damage in PC12 cells. Food Funct. 2015;6(6):2091-2100. doi:10.1039/c5fo00097a

48. Yu H, Liu P, Tang H, et al. Oleuropein, a natural extract from plants, offers neuroprotection in focal cerebral ischemia/reperfusion injury in mice. Eur J Pharmacol. 2016;775:113-119. doi:10.1016/j.ejphar.2016.02.027

49. Impellizzeri D, Esposito E, Mazzon E, et al. The effects of a polyphenol present in olive oil, oleuropein aglycone, in an experimental model of spinal cord injury in mice. Biochem Pharmacol. 2012;83 (10):1413-1426. doi:10.1016/j.bcp.2012.02.001

50. Khalatbary AR, Ahmadvand H. Neuroprotective effect of oleuropein following spinal cord injury in rats. Neurol Res. 2012;34(1):44-51. doi:10.1179/1743132811Y.0000000058

51. Rigacci S, Guidotti V, Bucciantini M, et al. Oleuropein aglycon prevents cytotoxic amyloid aggregation of human amylin $\square$. J Nutr Biochem. 2010;21(8):726-735. doi:10.1016/j.jnutbio.2009.04.010

52. Luccarini I, Grossi C, Rigacci S, et al. Oleuropein aglycone protects against pyroglutamylated-3 amyloid- $\beta$ toxicity: biochemical, epigenetic and functional correlates. Neurobiol Aging. 2015;36(2):648663. doi:10.1016/j.neurobiolaging.2014.08.029

53. Pasban-Aliabadi H, Esmaeili-Mahani S, Sheibani V, Abbasnejad M, Mehdizadeh A, Yaghoobi MM. Inhibition of 6-hydroxydopamineinduced PC12 cell apoptosis by olive (Olea europaea L.) leaf extract is performed by its main component oleuropein. Rejuvenation Res. 2013;16(2):134-142. doi:10.1089/rej.2012.1384 
54. Visioli F, Galli C, Galli G, Caruso D. Biological activities and metabolic fate of olive oil phenols. Eur J Lipid Sci Tech. 2002;104:677-684. doi:10.1002/1438-9312(200210)104:9/10<677:: AID-EJLT677>3.0.CO;2-M

55. Boskou D. Olive Oil: Chemistry and Technology. 2nd ed. AOCS Publishing; 2006.

56. de la Puerta R, MEM D, Ruíz-Gutíerrez V, Flavill JA, Hoult JRS. Effects of virgin olive oil phenolics on scavenging of reactive nitrogen species and upon nitrergic neurotransmission. Life Sci. 2001;69:1213-1222. doi:10.1016/s0024-3205(01)01218-8

57. Visioli F, Caruso D, Galli C, Viappiani S, Galli G, Sala A. Olive oils rich in natural catecholic phenols decrease isoprostane excretion in humans. Biochem Biophys Res Commun. 2000;278:797-799. doi:10.1006/bbrc.2000.3879

58. Coni E, Di Benedetto R, Di Pasquale M, et al. Protective effect of oleuropein, an olive oil biophenol, on low density lipoprotein oxidizability in rabbits. Lipids. 2000;35:45-54. doi:10.1007/s11745-000-0493-2

59. de la Puerta R, Gutierrez VR, Hoult JRS. Inhibition of leukocyte 5lipoxygenase by phenolics from virgin olive oil. Biochem Pharmacol. 1999;57:445-449. doi:10.1016/s0006-2952(98)00320-7

60. Carluccio MA, Siculella L, Ancora MA, et al. Olive oil and red wine antioxidant polyphenols inhibit endothelial activation: antiatherogenic properties of Mediterranean diet phytochemicals. Arterioscler Thromb Vasc Biol. 2003;23:622-629. doi:10.1161/01.ATV.0000062884.69432.A0

61. Hamdi HK, Castellon R. Oleuropein, a non-toxic olive iridoid, is an anti-tumor agent and cytoskeleton disruptor. Biochem Biophys Res Commun. 2005;334:769-778. doi:10.1016/j.bbrc.2005.06.161

62. Menendez JA, Vazquez-Martin A, Colomer R, et al. Olive oil's bitter principle reverses acquired autoresistance to trastuzumab (Herceptin $^{\mathrm{TM}}$ ) in HER2-overexpressing breast cancer cells. BMC Cancer. 2007;7:80. doi:10.1186/1471-2407-7-80

63. Han J, Talorete TPN, Yamada P, Isoda H. Anti-proliferative and apoptotic effects of oleuropein and hydroxytyrosol on human breast cancer MCF-7 cells. Cytotechnology. 2009;59:45-53. doi:10.1007/ s10616-009-9191-2
64. Goulas V, Exarchou V, Troganis AN, et al. Phytochemicals in oliveleaf extracts and their antiproliferative activity against cancer and endothelial cells. Mol Nutr Food Res. 2009;53:600-608. doi:10.1002/ mnfr.200800204

65. Bisignano G, Tomaino A, Cascio RL, Crisafi G, Uccella N, Saija A. On the in-vitro antimicrobial activity of oleuropein and hydroxytyrosol. J Pharm Pharmacol. 1999;51:971-974. doi:10.1211/0022357991773258

66. Aziz NH, Farag SE, Mousa LA, Abo-Zaid MA. Comparative antibacterial and antifungal effects of some phenolic compounds. Microbios. 1998;93:43-54.

67. Furneri PM, Marino A, Saija A, Uccella N, Bisignano G. In vitro antimycoplasmal activity of oleuropein. Int $J$ Antimicrob Agents. 2002;20:293-296. doi:10.1016/s0924-8579(02)00181-4

68. Sudjana AN, D’Orazio C, Ryan V, et al. Antimicrobial activity of commercial Olea europaea (olive) leaf extract. Int $J$ Antimicrob Agents. 2009;33:461-463. doi:10.1016/j.ijantimicag.2008.10.026

69. Tassou CC, Nychas GJ, Board RG. Effect of phenolic compounds and oleuropein on the germination of bacillus cereus $\mathrm{T}$ spores. Biotechnol Appl Biochem. 1991;13:231-237.

70. Tassou CC, Nychas GJE. Inhibition of salmonella enteritidis by oleuropein in broth and in a model food system. Lett Appl Microbiol. 1995;20:120 124. doi:10.1111/j.1472-765x.1995.tb01301.x

71. Tassou CC, Nychas GJE. Inhibition of staphylococcus aureus by olive phenolics in broth and in a model food system. J Food Prot. 1994;57:120-124. doi:10.4315/0362-028X-57.2.120

72. Tranter HS, Tassou SC, Nychas GJ. The effect of the olive phenolic compound, oleuropein, on growth and enterotoxin B production by staphylococcus aureus. J Appl Bacteriol. 1993;74:253-259. doi:10.1111/j.1365-2672.1993.tb03023.x

73. Fredrickson WRF, S Group, Inc. Method and composition for antiviral therapy with olive leaves.U.S. Patent. 2000;6:117:884.

74. Ma SC, He ZD, Deng XL, et al. In vitro evaluation of secoiridoid glucosides from the fruits of ligustrum lucidum as antiviral agents. Chem Pharm Bull (Tokyo). 2001;49:1471-1473. doi:10.1248/cpb.49.1471
Neuropsychiatric Disease and Treatment

\section{Publish your work in this journal}

Neuropsychiatric Disease and Treatment is an international, peerreviewed journal of clinical therapeutics and pharmacology focusing on concise rapid reporting of clinical or pre-clinical studies on a range of neuropsychiatric and neurological disorders. This journal is indexed on PubMed Central, the 'PsycINFO' database and CAS, and is the official journal of The International Neuropsychiatric Association (INA). The manuscript management system is completely online and includes a very quick and fair peer-review system, which is all easy to use. Visit http://www.dovepress.com/testimonials.php to read real quotes from published authors. 